\title{
Effect of Nursing Instructions on Life Style of Patients Receiving Radioactive Iodine Therapy for Thyroid Disorders
}

\author{
Salwa A. Algaid ${ }^{1}$, Zienab Abd El-lateef Mohammad², Sahar A. Abd-El Mohsen ${ }^{3}$ \& Hemat A. El Samie ${ }^{4}$. \\ Master Degree in Medical Surgical Nursing, Egypt. \\ Professor of Medical Surgical Nursing, Faculty of Nursing, Assuit University, Egypt. \\ Lecturer of of Medical Surgical Nursing, Faculty of Nursing, Assiut University, Egypt. \\ Lecturer of Nuclear Medicine, Faculty of Medicine, Assiut University, Egypt.
}

\begin{abstract}
Radioactive iodine therapy is the most common treatment for Graves' disease and toxic multi-nodular goiter in adult Aim: to evaluate the effect of nursing instructions on life style of thyroid disorders patients receiving radioactive iodine therapy (RAI). Patients and methods: the study was conducted in Nuclear Medicine department of Assiut university hospital and South Egypt Cancer Institute. A convenience sample (60) adult thyroid disorder patients from both sex, who were admitted in the Nuclear Medicine department for RAI therapy. Tools Patient interview Questionnaire, patient's life style questionnaire: (Walker, K. Sechirst, N. Pender., 1995) and designed nursing instructions booklet Results: the study group patient achieved a satisfactory level of knowledge after application of the nursing instructions (86.7\%). There was a highly statistically significant difference between the study group pre \& post implementation of the nursing instructions (P.v 0.001). Conclusion: there was an improvement in knowledge level after implementation of the nursing instructions in the study group, $86.7 \%$, there was a highly statistically significant difference between the study group patients pre and post application of nursing instructions. An improvement of life style in the study group after implementation of nursing instructions. Recommendations: Equip the nuclear unit with: nursing instructions booklet covering instructions about improving life style of patients receiving RAI therapy.
\end{abstract}

Key words: Nursing Instructions, Improvement Life Style \& RAI Therapy.

\section{Introduction}

The thyroid gland is located in the lower portion of the anterior neck. It consists of two lobes, one on each side of the trachea. The lobes are connected in front of the trachea by a narrow bridge of tissue called the isthmus. The thyroid gland plays a major role in regulating the body's rate of metabolism and growth and development. (Linton, 2013)

A healthy person produces just enough thyroid hormone to meet their needs. Levels rise and fall according to the environment and the level of activity. The biological term is homeostasis, each cell, each tissue, each organism aims to compensate for internal and external changes and keep the body's critical functions within a narrow range. It's a bit like using a thermo state on a central heating system to keep the house at a comfortable temperature, for example, when it,s cold thyroid hormone production rises, in response cells convert more fuel to energy, which generates heat (Greener, 2014).

The term of hyperthyroidism is used when the mean metabolic rate of all cells is increased due to increased $\mathrm{T} 4$ or $\mathrm{T} 3$. Clinical features include tachycardia, palpitations, nervousness, diaphoresis, heat intolerance, weakness, tremors, diarrhea, and weight loss despite a good appetite, lab studied show elevated free $\mathrm{T} 4$, in primary hyperthyroidism $\mathrm{TSH}$ is decreased and in secondary and tertiary hyperthyroidism TSH is elevated (Barone \& Castro, 2017).

Radioactive iodine (RAI) therapy is the treatment of choice for most non pregnant women. RAI damages or destroys thyroid tissue, thus limiting thyroid hormone secretion. RAI has a delayed response, and maximum effect may not be seen up for 3 months. For this reason, the patient is usually treated with ant thyroid drugs and $\beta$ blockers before and for up to 3 months after the initiation of RAI until the effects become apparent. (Brown et al., 2015)

Patients should be informed that radioiodine, antithyroid drugs and surgery are all reasonable treatment options for hyperthyroidism. It is crucial for the physician to have detailed discussion with the patient about the benefits and risks relative to lifestyle, patient's values and coexisting conditions. ( Ferri, 2016)

Living a healthy lifestyle means getting enough exercise, exercise boost the functions of all parts of the body and that includes the thyroid gland and also counter the effects of thyroid diseases such as weight gain and heart disease, living healthy life style throught exercise can help the patient to benefit from thyroid diet to keeping the thyroid healthy (Samons, 2012). 


\section{Significance of the Study}

Patients with thyroid disorders and receiving radioactive iodine have many physical, social, and emotional problems that affect their life style.

According to Statistical Report at Assiut University Hospital, the number of patients receiving radioactive iodine was approximately (140) and (128) in South Egypt Cancer Institute in 2016.

Nursing instructions for patients has a very important role before, during and after the therapy to limit radioactive iodine complication and improve patient's physical, social and emotional problems.

\section{Aim of the study}

The aim of this study was to evaluate the effect of nursing instructions on life style of patients' receiving radioactive iodine for treatment of thyroid disorders.

\section{Hypotheses}

1. Patients who will receive the nursing instructions will be better regarding physical, social and emotional condition than those patients who will not receive the nursing instructions.

2. Patients who will receive the nursing instructions will have a better life style than those patients who will not receive the nursing instructions.

\section{Patients \& Method}

\section{Research design}

Quasi experimental research design was utilized in this study

\section{Setting of the study}

This study was carried out at the Nuclear Medicine department of Assiut university hospital and South Egypt Cancer Institute.

\section{Study patients}

A sample of (60) adult thyroid disorder patients from both sexes. Patients who were admitted in the Nuclear Medicine Department for receiving radioactive iodine therapy were included in this study. Those patients were equally divided into 2 groups, study and control group (30) patients for each. The study group were received the nursing instructions while the control group received the routine hospital care.

Sample size: the sample size was calculated using the epi- info program with confidence level at $95 \%$ and the flow rate of patients 268 cases in 6 months and the sample was calculated to be 60 patients 30 for the study group and 30 for the control group.

Tools of the study

Tool I: Patient Interview Questionnaire Sheet: It was designed by the researcher to assess patient's physical, social and emotional status after reviewing national and international literature under supervisors' guidance.
This tool was divided into 3 parts:

Part (1): Patients Socio-Demographic and Medical Data sheet:

A. Socio demographic data: - age, gender, marital status, level of education, and occupation.

B. Patients' Medical Data; It include; Patient diagnosis, previous cancer, and chronic disease (diabetes mellitus, hypertension, and cardiovascular disease), smoking and family history, laboratory tests, pregnancy test, breast feeding/lactating women, bladder and bowel control and mental state.

Part (2): Assessment of patients' knowledge regarding radioactive iodine therapy includes; definition of radioactive iodine therapy, preparation for radioactive iodine therapy, route of administration, side effects, contraindications of radioactive iodine therapy, how radioactive iodine is excreted, and use of radioactive iodine in diagnosis.

Part (3): Assessment of patient's physical, social and emotional problems: it was used to assess patient's physical, social and emotional problems, it comprises 33 items, physical problems (23 items), emotional problems (6 items), social problems (4 items).

Tool II: patient's life style questionnaire: (Walker, K. Sechirst, N. Pender., 1995) it was used to assess the patient's life style: It comprises 52 items, which measure the following broad domains: Interpersonal Relations (9 items), health Responsibility (9 items), Nutrition (9 items), Stress Management (8 items), Physical Activity (8 items), Spiritual Growth (9 items), measurement of overall life style of patient.

\section{Scoring system}

$\operatorname{Never}(\mathrm{N})=1$

Sometimes $(\mathrm{S})=2$

Often $(\mathrm{O})=3$

Routinely $(\mathrm{R})=4$

To calculate the score for overall health-promoting lifestyle, calculate the mean of all 52 questions.

To calculate the score for each of the six subscales, calculate the mean of the responses to subscale items. Tool III: Designed nursing instructions booklet: This tool was developed by the researcher based on patients assessment needs after reviewing current national and international literature to improve life style of patients receiving radioactive iodine. It was formulated and introduced to the study group patients in the form of sessions. The nursing instructions booklet was written in Arabic simple language and it included knowledge about: thyroid gland, function, thyroid disorder, patient physical, social and emotional problems and how to deal with them, definition of radioactive iodine therapy, indications, side effects and contraindications of radioactive iodine therapy, preparation for therapy, instructions 
for patient daily living activities, signs and symptoms of complications, follow-up appointments.

\section{Tools testing and pilot study}

- An official letter was issued from the Dean of the Faculty of Nursing to the Head of the Nuclear Medicine department at Assiut university hospital and head of South Egypt Cancer Institute soliciting the necessary approval to conduct the present research, to obtain their cooperation.

- The final form of the Nursing instructions and assessment tools was checked by a panel of experts from the field of medical surgical nursing $\&$ oncology medicine for content validity and reliability

- A pilot study was implemented on (10\%) 6 patients to examine the feasibility of the study. Analyses of the pilot study revealed that minimal modifications are required. These modifications were done and the pilot study patients were excluded from the actual study.

\section{Field work}

- A structured interview was utilized to fill out the Patient Interview Questionnaire Sheet (tool I) and data were collected from the Nuclear Medicine department at Assiut university hospital and South Egypt Cancer Institute, during the period from 1/5 /2017 to $1 / 12 / 2017$.

- The tools (tool I part 1, 2, 3 and tool II filled through interviewing after explaining the purpose of the study to the patients prior to answering the questions, the study was carried out at morning, and noon period.

- The researcher explained to the patients the designed nursing instructions in the following sequence. The designed nursing teaching was administered to the patient in four sessions, the duration of each session ranged between 30-45 minutes according to the level of understanding of each patient.

- The first session: The researcher started by introducing herself to the patient telling her/him about the aim of the meeting, orient patient regarding the designed nursing teaching instructions. Contents of this session were; brief illustration of the anatomy of the thyroid gland, definition of thyroid disorder and causes or risk factors for thyroid disorder, signs and symptoms of thyroid disorders, diagnosis and treatment of thyroid disorders. The session ended by a summary of its content and feedback from patients.

- The second session: summary about what has been discussed in the previous session, objective of the new session, contents of this session includes: information about radioactive iodine therapy (definition of radioactive iodine therapy, preparation of patient, mode of administrations, instructions for patients during and after therapy, side effects of radioactive iodine therapy, how to clear the radioactive iodine from patients body, diet before and after radioactive iodine therapy, taking medication as instructed by doctor.

- The third session: summary about what has been discussed in the previous session, objective of the new session, and instructions for healthy life style, and follow up. Eat mostly foods derived from plants -vegetables, fruits, whole grains and legumes (beans, peas, lentils) - and limit highly processed foods, drink plenty of water, reduce sugar intake, avoiding caffeine in the afternoon and evening improves the quality of sleep, patients should avoid too much noise at night, getting rest and enough sleep, daily exercise regimen, coping better with stress, relaxation techniques such as meditation, yoga, ended the session by a summary of its content and feedback from patients.

- Study and control group patients were evaluated after 3 months using tool I part (2) and part (3) and tool II.

\section{Ethical considerations}

1. Research proposal was approved from Ethical Committee in the faculty of nursing.

2. There is no risk for study patients during application of the research.

3. The study followed common ethical principles in clinical research.

4. Oral consent was obtained from patients who are willing to participate in the study, after explaining the nature and purpose of the study.

5. Confidentiality and anonymity were assured.

6. Study patients have the right to refuse to participate and or withdraw from the study without any rational any time.

7. Study patients privacy was considered during collection of data.

\section{Statistical design}

The data obtained reviewed, prepared for computer entry, coded, analyzed and tabulated. Descriptive statistics (frequencies and percentages, mean and standard deviation) were done using computer program (SPSS) version (22). Independent sample $\mathrm{T}$ test, Chi-square and One-way-anova tests used in relationship between study and control groups' physical \& psychological assessment, knowledge and complications. It's considered significant when P. value less than (0.05). 


\section{Results}

Table (1): Distribution of the studied patient's regarding their socio-demographic data.

\begin{tabular}{|c|c|c|c|c|c|c|}
\hline \multirow{2}{*}{ Items } & \multicolumn{2}{|c|}{ Study Group n = 30} & \multicolumn{2}{|c|}{ Control Group n=30 } & \multirow{2}{*}{ F-test } & \multirow{2}{*}{ P-value } \\
\hline & N. & $\%$ & N. & $\%$ & & \\
\hline \multicolumn{5}{|l|}{ Age: } & \multirow{6}{*}{2.205} & \multirow{6}{*}{0.116} \\
\hline $18 \mathrm{Y}$ to $<40 \mathrm{Y}$ & 16 & 53.3 & 15 & 50.0 & & \\
\hline $40 \mathrm{Y}$ to $<60 \mathrm{Y}$ & 12 & 40.0 & 9 & 30.0 & & \\
\hline $60 \mathrm{Y}$ to $65 \mathrm{Y}$ & 2 & 6.7 & 6 & 20.0 & & \\
\hline Mean \pm SD & \multicolumn{2}{|c|}{$35.8 \pm 12.4$} & \multicolumn{2}{|c|}{$42.5 \pm 16.4$} & & \\
\hline Range & \multicolumn{2}{|c|}{$18.0-61.0$} & \multicolumn{2}{|c|}{$18.0-65.0$} & & \\
\hline \multicolumn{5}{|l|}{ Gender: } & \multirow{3}{*}{4.934} & \multirow{3}{*}{0.100} \\
\hline Male & 3 & 10.0 & 6 & 20.0 & & \\
\hline Female & 27 & 90.0 & 24 & 80.0 & & \\
\hline \multicolumn{5}{|l|}{ Marital Status: } & \multirow{5}{*}{1.614} & \multirow{5}{*}{0.209} \\
\hline Single & 9 & 30.0 & 3 & 10.0 & & \\
\hline Married & 19 & 63.3 & 24 & 80.0 & & \\
\hline Divorced & 0 & 0.0 & 1 & 3.3 & & \\
\hline Widow & 2 & 6.7 & 2 & 6.7 & & \\
\hline \multicolumn{5}{|l|}{ Educational Level: } & \multirow{6}{*}{1.055} & \multirow{6}{*}{0.309} \\
\hline High education & 3 & 10.0 & 5 & 16.7 & & \\
\hline Secondary education & 11 & 36.7 & 8 & 26.7 & & \\
\hline Basic education & 1 & 3.3 & 2 & 6.7 & & \\
\hline Read and write & 1 & 3.3 & 6 & 20.0 & & \\
\hline Illiterate & 14 & 46.7 & 9 & 30.0 & & \\
\hline \multicolumn{5}{|l|}{ Occupation: } & \multirow{5}{*}{3.855} & \multirow{5}{*}{0.054} \\
\hline Employee & 4 & 13.4 & 8 & 26.7 & & \\
\hline Farmer & 1 & 3.3 & 4 & 13.3 & & \\
\hline House wife & 21 & 70.0 & 18 & 60.0 & & \\
\hline Student & 4 & 13.3 & 0 & 0.0 & & \\
\hline
\end{tabular}

Independent sample T-test

* Statistical significant differences $(p<0.05$

Table (2): Distribution of the studied patients regarding their medical data.

\begin{tabular}{|c|c|c|c|c|c|c|}
\hline \multirow{2}{*}{ Items } & \multicolumn{2}{|c|}{ Study Group( $n=30)$} & \multicolumn{2}{|c|}{ Control Group $(\mathrm{n}=\mathbf{3 0})$} & \multirow{2}{*}{ F-test } & \multirow{2}{*}{$\begin{array}{c}\text { P- } \\
\text { value }\end{array}$} \\
\hline & $\mathbf{N}$. & $\%$ & $\mathbf{N}$. & $\%$ & & \\
\hline \multicolumn{5}{|l|}{ Medical history: } & \multirow{7}{*}{3.512} & \multirow{7}{*}{0.066} \\
\hline No history & 26 & 86.7 & 21 & 70.0 & & \\
\hline High blood pressure & 2 & 6.7 & 3 & 10.0 & & \\
\hline Heart disease & 1 & 3.3 & 1 & 3.3 & & \\
\hline Diabetes & 1 & 3.3 & 5 & 16.7 & & \\
\hline Kidney disease & 0 & 0.0 & 0 & 0.0 & & \\
\hline Hepatic disease & 0 & 0.0 & 0 & 0.0 & & \\
\hline \multicolumn{5}{|l|}{ Surgical history: } & \multirow{7}{*}{3.798} & \multirow{7}{*}{0.069} \\
\hline No surgical history & 5 & 16.7 & 2 & 6.7 & & \\
\hline Back surgery & 0 & 0.0 & 0 & 0.0 & & \\
\hline Knee surgery & 0 & 0.0 & 0 & 0.0 & & \\
\hline Heart surgery & 1 & 3.3 & 1 & 3.3 & & \\
\hline Neck surgery (thyroidectomy) & 24 & 80.0 & 26 & 86.7 & & \\
\hline Others & 0 & 0.0 & 1 & 3.3 & & \\
\hline \multicolumn{5}{|l|}{ Risk factors for thyroid disease } & \multirow{2}{*}{0.246} & \multirow{2}{*}{0.622} \\
\hline No & 26 & 86.8 & 26 & 86.8 & & \\
\hline
\end{tabular}




\begin{tabular}{|c|c|c|c|c|c|c|}
\hline \multirow{2}{*}{ Items } & \multicolumn{2}{|c|}{ Study Group( $n=30)$} & \multicolumn{2}{|c|}{ Control Group $(n=30)$} & \multirow{7}{*}{ F-test } & \multirow{7}{*}{$\begin{array}{c}P- \\
\text { value }\end{array}$} \\
\hline & N. & $\%$ & N. & $\%$ & & \\
\hline Hypertension & 1 & 3.3 & 1 & 3.3 & & \\
\hline Tobacco use & 0 & 0.0 & 0 & 0.0 & & \\
\hline Diabetes mellitus & 2 & 6.6 & 1 & 3.3 & & \\
\hline Unhealthy diet & 1 & 3.3 & 1 & 3.3 & & \\
\hline Hypertension & 0 & 0.0 & 1 & 3.3 & & \\
\hline \multicolumn{5}{|l|}{ Family history: } & \multirow{6}{*}{0.163} & \multirow{6}{*}{0.688} \\
\hline No family history & 29 & 96.7 & 28 & 93.3 & & \\
\hline Cancer & 0 & 0.0 & 1 & 3.3 & & \\
\hline Heart disease & 0 & 0.0 & 0 & 0.0 & & \\
\hline Thyroid disorders & 1 & 3.3 & 1 & 3.3 & & \\
\hline Kidney disease & 0 & 0.0 & 0 & 0.0 & & \\
\hline
\end{tabular}

Independent sample T-test

* Statistical significant differences $(p<0.05)$

Table (3): Percentage distribution of the studied patients' regarding their knowledge level pre $\&$ post implementation of the nursing instructions.

\begin{tabular}{|c|c|c|c|c|c|c|c|c|c|c|c|}
\hline \multirow{3}{*}{ Patients' knowledge } & \multicolumn{4}{|c|}{ Study group $(n=30)$} & \multicolumn{4}{|c|}{ Control group $(n=30)$} & \multirow{3}{*}{ P1 } & \multirow{3}{*}{$\mathbf{P 2}$} & \multirow{3}{*}{ P3 } \\
\hline & \multicolumn{2}{|c|}{ Pre } & \multicolumn{2}{|c|}{ Post } & \multicolumn{2}{|c|}{ Pre } & \multicolumn{2}{|c|}{ Post } & & & \\
\hline & N. & $\%$ & $\mathbf{N}$. & $\%$ & N. & $\%$ & N. & $\%$ & & & \\
\hline Satisfactory Level & 3 & 10.0 & 26 & 86.7 & 4 & 13.3 & 5 & 16.6 & \multirow[t]{3}{*}{0.001} & \multirow[t]{2}{*}{0.889} & \multirow[t]{2}{*}{0.001} \\
\hline Unsatisfactory Level & 27 & 90.0 & 4 & 13.3 & 26 & 86.7 & 25 & 83.4 & & & \\
\hline Total & 30 & 100.0 & 30 & 100.0 & 30 & 100.0 & 30 & 100.0 & & NS & $* * *$ \\
\hline
\end{tabular}

One way ANOVA

* Statistical significant differences $(p<0.05)$

P1: Comparison between pre-study and post-study group

P2: Comparison between pre-study and pre-control groups

P3: Comparison between post-study and post-control groups

Table (4): Distribution of the studied patients' regarding their thyroid disorders for study (pre \& post) and control (pre \& post) groups.

\begin{tabular}{|c|c|c|c|c|c|c|c|c|c|c|c|}
\hline \multirow{3}{*}{ Physical disorders } & \multicolumn{4}{|c|}{ Study group $(n=30)$} & \multicolumn{4}{|c|}{ Control group $(n=30)$} & \multirow{3}{*}{ P1 } & \multirow{3}{*}{$\mathbf{P 2}$} & \multirow{3}{*}{ P3 } \\
\hline & \multicolumn{2}{|c|}{ Pre } & \multicolumn{2}{|c|}{ Post } & \multicolumn{2}{|c|}{ Pre } & \multicolumn{2}{|c|}{ Post } & & & \\
\hline & N. & $\%$ & N. & $\%$ & N. & $\%$ & N. & $\%$ & & & \\
\hline No disorder & 6 & 20.0 & 26 & 86.7 & 3 & 10.0 & 4 & 13.3 & \multirow{3}{*}{$\begin{array}{l}0.001 \\
* * *\end{array}$} & \multirow{3}{*}{$\begin{array}{l}0.825 \\
\text { NS }\end{array}$} & \multirow{3}{*}{$\begin{array}{l}0.001 \\
* * *\end{array}$} \\
\hline Present & 24 & 80.0 & 4 & 13.3 & 27 & 90.0 & 26 & 86.7 & & & \\
\hline Total & 30 & 100.0 & 30 & 100.0 & 30 & 100.0 & 30 & 100.0 & & & \\
\hline
\end{tabular}

One way ANOVA

* Statistical significant differences $(p<0.05)$

P1: Comparison between pre-study and post-study group

P2: Comparison between pre-study and pre-control groups

P3: Comparison between post-study and post-control groups

Table (5): Relation between the study group patients presenting signs / symptoms and their physical problems post implementing the nursing instructions.

\begin{tabular}{|c|c|c|c|c|c|}
\hline \multirow{3}{*}{ Items } & \multicolumn{4}{|c|}{ Post-Study group $(\mathrm{n}=30)$ physical problems } & \multirow{3}{*}{ P-value } \\
\hline & \multicolumn{2}{|c|}{ Present $(n=4)$} & \multicolumn{2}{|c|}{ Not present $(n=26)$} & \\
\hline & $\mathbf{N}$. & $\%$ & N. & $\%$ & \\
\hline \multicolumn{5}{|l|}{ Decrease activity: } & \multirow{3}{*}{0.674} \\
\hline Present & 2 & 16.7 & 10 & 83.3 & \\
\hline Not Present & 2 & 11.1 & 16 & 88.9 & \\
\hline \multicolumn{5}{|l|}{ Fatigue: } & \multirow{3}{*}{0.702} \\
\hline Present & 4 & 13.8 & 25 & 86.2 & \\
\hline Not Present & 0 & 0.0 & 1 & 100.0 & \\
\hline
\end{tabular}

Vol , (7) No , (17) June, 2019 


\begin{tabular}{|c|c|c|c|c|c|}
\hline \multirow{3}{*}{ Items } & \multicolumn{4}{|c|}{ Post-Study group $(n=30)$ physical problems } & \multirow{3}{*}{ P-value } \\
\hline & \multicolumn{2}{|c|}{ Present $(n=4)$} & \multicolumn{2}{|c|}{ Not present $(n=26)$} & \\
\hline & $\mathbf{N}$. & $\%$ & $\mathbf{N}$. & $\%$ & \\
\hline Dizziness: & & & & & \multirow{3}{*}{0.674} \\
\hline Present & 2 & 16.7 & 10 & 83.3 & \\
\hline Not Present & 2 & 11.1 & 16 & 88.9 & \\
\hline \multicolumn{5}{|l|}{ Nausea: } & \multirow{3}{*}{0.702} \\
\hline Present & 0 & 0.0 & 1 & 100.0 & \\
\hline Not Present & 4 & 13.8 & 25 & 86.2 & \\
\hline \multicolumn{5}{|l|}{ Sore throat: } & \multirow{3}{*}{0.618} \\
\hline Present & 1 & 9.1 & 10 & 90.9 & \\
\hline \multicolumn{5}{|l|}{ Not Present } & \\
\hline Dyspnea: & & & & & \multirow{3}{*}{0.581} \\
\hline Present & 0 & 0.0 & 2 & 100.0 & \\
\hline Not Present & 4 & 14.3 & 24 & 85.7 & \\
\hline \multicolumn{5}{|l|}{ Syncope: } & \multirow{3}{*}{-} \\
\hline Present & 0 & 0.0 & 0 & 0.0 & \\
\hline Not Present & 4 & 13.3 & 26 & 86.7 & \\
\hline
\end{tabular}

Table (6): Pearson correlation coefficient to determine the effect of the thyroid disorders of the study \& control; patients on Life style.

\begin{tabular}{|l|c|c|c|}
\hline \multicolumn{1}{|c|}{ Life style / thyroid disorders } & Physical & Emotional & Social \\
\hline \multicolumn{1}{|c|}{ Health Responsibility } & $0.453^{* *}$ & $0.453^{* *}$ & $0.653^{*}$ \\
\hline Physical Activity & $0.657^{* *}$ & $0.326^{*}$ & $0.543^{*}$ \\
\hline Nutrition & $0.435^{* *}$ & $0.342^{* *}$ & $0.546^{*}$ \\
\hline Spiritual Growth & $0.342^{* *}$ & $0.473^{* *}$ & $0.496^{*}$ \\
\hline Interpersonal Relations & $0.373^{*}$ & $0.768^{*}$ & $0.231^{*}$ \\
\hline Stress Management & $0.352^{*}$ & $0.342^{*}$ & $0.546^{*}$ \\
\hline
\end{tabular}

$P$-values for the correlation: $\quad * * P<0.01 \quad \& \quad * P<0.05$.

Table (1): Shows that; most of patients are female in both samples $(90 \%, 80 . \%$ respectively). More than half of patients their age ranged from $18<40$ years in both samples $(53.3 \%, 50 . \%$ respectively). Vast majority of patients are married $(63.3 \%, 80.0 \%$ respectively). One third of patients are illiterate (46.7\%, $30 \%$ respectively). Vast majority of patients are house wives (70.0\%, $60.0 \%$ respectively).

Table (2): Found that, Vast majority of the patients in both samples, the majority of patients had no medical history, $80 \%$ of the study group and 86.7 in the control group respectively, while the majority of patients had neck surgery (thyroidectomy) $80 \%$ in the study group and $86 \%$ of the control group, no risk factor for thyroid disorder $86.8 \%$ in both groups, no family history $96.7 \%$ in the study group and $93.3 \%$ in the control group. had no medical history, $80 \%$ of the study group and 86.7 in the control group respectively.

Table (3): This table shows that, there was no statistically significant difference between the study $\&$ control groups regarding their knowledge level pre implementation of the nursing teaching instructions, while a highly statistically significant difference was found between the study group patients pre and post application of the nursing teaching instructions.

Table (4): This table shows that, there was a statistically significant difference between pre-study and post-study group and between post-study and post-control groups $0.001 * * *$

Table (5): This table reveals that no statistically significant difference was found between the study group patients presenting signs / symptoms \& their physical problems post implementation of the nursing instructions.

Table (6): This table illustrates a statistically significant correlation between life style domains \& physical, emotional \& social problems of the study \& control group patients.

\section{Discussion}

The aim of this study was to evaluate the effect of nursing instructions on life style of patients' 
receiving radioactive iodine for treatment of thyroid disorders.

The present study results presented that the majority of the sample (study and control) were in the age group from $18<40$ yrs. old, Abd elrazik, (2010), agree with this results when they stated that, the majority of the sample was between 20- 30 years old. Hammoodi \& Khudur, (2015), disagree with this result when they stated that the large prevalence of hyperthyroidism was in the patient with age (40 50) and Mohamed, (2016), who found that the majority of patients in his study sample their age was more than 50 years old.

The current study results revealed that the majority of the sample in both groups were female $90.0 \%$ in the control group and $80.0 \%$ in the study group, this result was in agreement with the study of Hammoodi \& Khudur, (2015) who reported that the highest percentage of the patients were female $(69 \%)$ while (31\%) were male. And also agree with Shao et al., (2017), who reported that the majority of the sample were female $(64.3 \%)$, also this results agree with Ibrahim, (2016), who reported that the majority of sample female.

Regarding marital status, the present study $63.3 \%$ in the study group and $80.0 \%$ in the control group were married, this agree with Hammond \& Khudur, (2015), who declared that most of patients were married (69\%) and also agree with Mohamed, (2016), who mentioned that nearly the entire studied sample was married.

The current study revealed that the majority of the sample in both groups were house wives $(70 \%)$ in the study group and $(60 \%)$ in the control group and this disagree with Hammoodi \& Khudur, (2015), who reported that majority of patients free work and were accounted (38\%), and also disagree with Mohamed, (2016), who reported that more than three quarters of the sample (study and control) was employee, less than one fifth were free business and a few of them were skilled workers.

Regarding knowledge about the disease, pre application of the nursing teaching instructions, in the study group one third were at satisfied level of knowledge and the majority of them achieved a satisfactory level of knowledge after application of the nursing teaching instructions and this agree with Mohamed, (2016) who reported that more than two thirds of patients have incomplete correct definition and symptoms of the diseases (ischemic heart disease) and all of them have complete answer after application of the teaching protocol.

The present study found that regarding level of education, the majority of patients were illiterate in both groups, (study \& control) and this disagree with Hammoodi \& Khudur, (2015), who found that the majority of patients with hyperthyroidism were secondary school graduate (the intermediate education level), this finding disagree with Mohamed, (2016), who revealed more than one third of the sample were secondary graduated, and this comes in the same line with Ibrahim, (2016) who reported that sixty percent of patients were illiterate, from the point of the researcher view this result may be related to that highly educated people are usually well informed about health issues including thyroid disorder and more prone to adopt healthy lifestyle habits such as a healthy diet, exercise, and the maintenance of an ideal body weight, moreover, educated people maintain a greater sense of control over their lives and tend to have a greater level of social support than those with a lower level of education.

The finding of this study revealed that the majority of patients in both groups before implementation of nursing instructions had fatigue with a statistically significant difference between the control and the study groups regarding dizziness $0.001 * * *$ and nausea $0.038^{*}$ and this comes in agreement $\mathrm{w}$ The current study revealed that the majority of patients in both groups, were not having family history for thyroid disorders. And this disagree with Hammoodi \& Khudur, (2015), who reported that the highest percent of the studied patients in their study were having family history, of hyperthyroidism.

The present study revealed that less than half of patient of study group and half of control group patients had decreased of physical activity pre implementation of nursing teaching instructions, improvement in physical activity patients in study groups after implemented teaching nursing instructions and no change in patients in the control group and this disagree with Abd elrazik, (2010), who reported that $60 \%$ of patients had physical activity at home and $40 \%$ of patient had practice physical exercise, all of the patient from those were walking, this result agree with Mohamed, (2016) who revealed that the majority of patients after application of the nursing teaching protocol started to practice physical exercise, all of them were walking daily, and knew the benefit of exercise for their disease.

Our study revealed a highly statistically significant difference between the study group pre \& post implementation of the nursing instructions, there is an improvement in life style domain in patients post study, two third of patients in the study groups have not physical disorder, majority of patients can control in their stress and keeping social relation and share concerns with others and this agree with Arab et al., (2017), who declared that of lifestyle 
modifications interventions are: Weight, BMI (body mass index), MBF (Maximum Bite Force) of the trunk, and energy intake showed a strong significant reduction after 2 months in intervention group $(\mathrm{P}<$ 0.001).

The current study showed no statistically significant difference between the study \& control groups regarding their life style domains pre \& post implementing the nursing instructions, while there was a highly statistically significant difference between the study group pre $\&$ post implementation of the nursing instructions. Improvement of life style in the study group after implementation of nursing instructions, eating a healthy diet that is low in fat, high in fiber and includes lots of fruits and vegetables, coping with the disease made a big difference in how patients feel. Yoga, meditation, deep breathing, or just chilling out to some

The present study revealed that, there was an improvement in knowledge level after implementation of the nursing instructions in the study group, there was a highly statistically significant difference between the study group patients pre and post application of the nursing teaching instructions. But there was no statistically significant difference between the study \& control groups regarding their knowledge level pre implementation of the nursing instructions, and statistically significant differences was found between post-study and post-control groups Abdelrazek, (2010), in the same line with the current study findings stated that, patient's knowledge score levels regarding definition of illness, symptoms, interventions, treatment, complications, compliance, significantly improved.

\section{Conclusion}

An improvement in knowledge level and life style of the study group patients after application of the nursing instructions.

\section{Recommendations}

- Equip the nuclear unit with: Designed nursing instructions booklet covering all knowledge and instructions related to improving life style of patients and receiving radioactive iodine therapy.

- Develop an in service audiovisual materials training/education about thyroid gland and thyroid disorders and radioactive iodine therapy before, during and after procedure for patients.

- Newly employed nurses, technologist and workers in the nuclear medicine unit are required to successfully complete a test of basic knowledge and skills before assuming independent responsibility for patient care.

- Nurses should be encouraged to attend specific meetings as workshops and seminars held for thyroid disorder diseases and radioactive iodine therapy to be acquainted with the most advances in this area.

- Orientation programs on mass medias for measuring thyroid function in all adults beginning at age 35 years and every 5 years thereafter, noting that more frequent screening may be appropriate in high risk or symptomatic individuals.

- Reapply this research on a larger probability sample acquired from different geographical areas in Egypt for generalization.

\section{References}

1. Abdb Elrazik H., (2010): A nursing care program to acquire healthy life style patterns among rheumatic heart disease patients with valvular disorder.

2. Arab J., Karpen S., Dawson P., Arrese M., \& Trauner M., (2017): Bile Acids and Nonalcoholic Fatty Liver Disease: Molecular Insights and Therapeutic Perspectives, Hematology, VOL. 65, NO. 1, 2017.

3. Barone J., \& Castro M., (2017): USMLE step 1 lecture notes 2017: pathology, ch 25, Endocrine pathology, Simon and Schuster, New York, Pp. 259.

4. Brown D., Edwards H., Seaton L., \& Buckley T., (2015): Lewis's Medical- Surgical Nursing: Assessment and Management of Clinical Problems. $\quad 4^{\text {th }}$ Ed, Ch 46, Nursing management endocrine problems, P p . 1231.

5. Ferri F., (2016): Ferri's Netter Patient Advisor. Managing thyroid cancer Elsevier Health, Pp. 487.

6. Greener M., (2014): Coping with Thyroid Disease. Ch 3, Goiters and nodules SPCK,

7. Hammoodi M., \& Khudur K., (2015): Life Style for Adult Patients with Hyperthyroidism at Baghdad Teaching Hospital, IOSR Journal of Nursing and Health Science (IOSR-JNHS) eISSN: 2320-1959.p- ISSN: 2320-1940 Volume 4, Issue 6 Ver. III (Nov. - Dec. 2015), PP 63-69 www.iosrjournals.org.

8. Linton A., (2016): Introduction to medical surgical nursing, ch 47, Thyroid and parathyroid disorder, $6^{\text {th }}$ ed, Canda Pp.1036.

9. Mohamed Y., (2016): Effect of nursing teaching protocol on life style modification of male patients with ischemic heart disease. Pp81-91.

10. Mohsen M., Fareed M., El-Sheikh A., \& Abbas S., (2011): Effect of nursing management 
protocol on selected side effects of Interferon and Ribavirin among hepatitis C patients. Journal of American Science, 2011; 7(6), http://www.americanscience.org.

11. Shao F., Gao C., Wei L., Yang Y., Zhou Z., Liu J., Yang R., \& Ma1 W., Wang Y., Tian L., (2017): Prevalence, related lifestyle and metabolic risk factors of hypothyroidism in adults: across-sectional study in Gansu province, Northwestern China.

12. Simon \& Schuster, (2012): Thyroid Disease: Thyroid disease and your weight: The most important information you need to improve your health.

13. S.N. Walker, K., Sechrist, N., Pender, (1995): Reproduction without the author's express written consent is not permitted. Permission to use this scale may be obtained from: Susan Noble Walker, College of Nursing, University of Nebraska Medical Center, Omaha, NE 681985330 ,

https://www.unmc.edu/nursing/faculty/English_H PLPII.pdf 